\title{
Experimental process investigation of a latent heat energy storage system with a staggered heat exchanger with different phase change materials for solar thermal energy storage applications
}

\author{
Nikolas P. Tsolakoglou ${ }^{1}$, Maria K. Koukou ${ }^{1 *}$, Michalis Gr. Vrachopoulos ${ }^{1}$, Nikolaos \\ Tachos $^{1}$, Kostas Lymberis ${ }^{2}$, and Vassilis Stathopoulos ${ }^{3}$ \\ ${ }^{1}$ Technological Educational Institute of Sterea Ellada, Mechanical Engineering Department, Energy \\ and Environmental Research Laboratory, 34400 Psachna, Evia, Greece \\ ${ }^{2} Z \& X$ Mechanical Installations Ltd, 12 Agapinoros Street, 8049 Paphos Cyprus \\ ${ }^{3}$ Technological Educational Institute of Sterea Ellada, Department of Electrical Engineering, \\ Laboratory of Chemistry and Materials Technology, 34400 Psachna, Evia, Greece
}

\begin{abstract}
This work investigates melting and solidification processes of four different Phase Change Materials (PCM) used as latent heat thermal storage system. The experimental rig was consisted of an insulated tank, filled with the under investigation PCM, a staggered heat exchanger to supply or extract heat from the PCM cavity and a water pump to circulate Heat Transfer Fluid (HTF). Both charging (melting) and discharging (solidification) processes were conducted for two different HTF flow rates. The main scope of this work was to develop a first approach and to investigate the behaviour of PCM under various load conditions (different HTF flow rates). Results show that different HTF flow rates affect melting and solidification time periods; in both processes time was reduced while HTF flow rate was increased but in differentways due to the transition from conduction to convection heat transfer mechanisms.
\end{abstract}

\section{Introduction}

Solar energy has been extensively utilized in residential cooling/heating and DHW production systems. One of the most efficient methods to store thermal energy is Latent Heat Thermal Energy Storage (LHTES) via the integration of PCM, exploiting high values of latent heat [1]. LHTES can store 5-14 times more heat per unit volume than sensible storage materials, such as water [2]. However, these materials have low thermal conductivities requesting large power density. The energy stored can be recovered in a constant temperature which may easily be utilized by Heat Pumps. LHTES materials should exhibit certain properties as thermal, physical, kinetic and chemical. Paraffin waxes

\footnotetext{
*Corresponding author: mkoukou@mail.teiste.gr, m koukou@otenet.gr
} 
are promising materials because they exploit efficient energy storage in an optimal temperature range for integration into residential heating/cooling systems. Regarding the design of commercial thermal energy storage units, further investigation is required to assess the physical phenomena and successfully implement PCM. Their proper design must take into account material characteristics, desired storage rate, transient PCM heat exchange and required energy storage capacity. In order to overcome low conductivity, various methods have been proposed including the use of nano-particles or the use of fins to maximize heat transfer [3, 4].

There are many phase change materials in the market and the selection of the appropriate PCM to be used in a certain application must take into consideration various technical and material properties issues. Some of these issues are, melting temperature which should fulfill the application area requirements, latent heat, chemical stability and thermal conductivity. Various fin configurations have been proposed in literature [5-9] as they influence heat transfer mechanisms during phase change process. Dimension, type and number of fins are selected based on a compromise between possible heat transfer increase and energy storage requirement. Numerous authors have investigated both numerically and experimentally heat exchanger configurations with PCM, as latent heat thermal storage systems. Medrano et al. [7] compared different types of heat exchangers with RT35 as PCM and water as heat transfer fluid (HTF). Performance evaluation was based on the required time to fully melt a certain cavity with different types of heat exchangers. Results state that's taggered heat exchanger made of aluminum-fins-and copper-tubes widely used as evaporator or condenser in small air conditioning units, is by large the one with the highest average thermal power (above $1 \mathrm{~kW}$ ), showing the highest ratio of heat transfer area to external volume.

In this work, a study on melting and solidification time is performed for different PCM and different HTF flow rates using a staggered heat exchanger (HE). The experimental rig comprises an insulated heat storage tank, an HE, an air to water heat pump for cold water supply, a buffer tank with an electric heater for hot water supply, a circulation pump, a three-way temperature control valve, a flowmeter and thermocouples along with a data logger. The HE is made of copper tubes with aluminum fins. Experiments involved melting and solidification of the PCM, were conducted for different HTF flow rates, showing the feasibility of using the PCM as a thermal storage media. Higher efficiency could be achieved by optimizing the performance of the equipment and selecting PCM with higher thermal conductivity.

\section{Experimental methodology}

\subsection{Experimental setup description}

An experimental rig was designed and developed for the investigation of melting and solidification processes of four different PCM for different HTF flow rates. Fig. 1 shows the experimental set-up. The experimental rig comprised a well-insulated heat storage transparent glass tank allowing viewing of melting and solidification procedures and also constant monitoring with the use of a camera. The dimensions of the tank were: $600 \times 120 \times 80 \mathrm{~mm}$ (Length $\times$ Width x Depth). A staggered heat exchanger was immersed in the PCM cavity (HE technical data are given in Table 1 and a 3D drawing in Fig. 2). Hot water was supplied by an $80 \mathrm{lt}$ boiler with a $4 \mathrm{Kw}$ electric heater and cold water was supplied by a $200 \mathrm{lt}$ water buffer tank connected to an air to water heat pump. 
Table 1. Staggered heat exchanger characteristics.

\begin{tabular}{|c|c|}
\hline Number of tubes & 12 \\
\hline Inner tube diameter $(\mathrm{mm})$ & 7.75 \\
\hline Outer tube diameter $(\mathrm{mm})$ & 9.525 \\
\hline Tube material & Copper \\
\hline Fins material & Aluminium \\
\hline Fin thickness $(\mathrm{mm})$ & 0,3 \\
\hline Fin length $(\mathrm{mm})$ & 68 \\
\hline Fin spacing $(\mathrm{mm})$ & 5.0 \\
\hline
\end{tabular}

The experimental rig also included a circulation pump (Grundfos ${ }^{\circledR}$ ALPHA 2 32-60 180 inverter pump), a three-way temperature control valve (Belimo ${ }^{\circledR}$ LR24A-SR valve and Vector $^{\mathbb{B}}$ TCI-W11 controller), a flow meter (rotameter with measuring range of $6-60 \mathrm{lt} / \mathrm{h}$ ), thermocouples ( $\mathrm{T}$ type), data logger (National instrument ${ }^{\circledR} \mathrm{cDAq}-9174$ base, 2 x 921316 ch cards, LabVIEW ${ }^{\circledR}$ data logger) and, finally, the necessary piping and valves to regulate water flow. The rig allows replacing easily phase change material and the heat exchanger as well. Thermal insulation has been applied on the outer side of the tank. HTF used is water. The volume between the tubes and the fins and the tank is filled with PCM. The hot HTF supplied from hot water buffer exchanges its heat and melts the PCM during the charging process. The heat is stored in the molten PCM. During discharging process, the cold HTF supplied by the cold water buffer tank flows through the tube and solidifies the molten PCM. The stored energy is released from the PCM as it solidifies.

To analyse HE thermal performance along with charging and discharging process, temperature measurements are performed on HTF inlet and outlet temperature and also within the PCM volume (positioning of the thermocouples are indicated in Fig. 3).

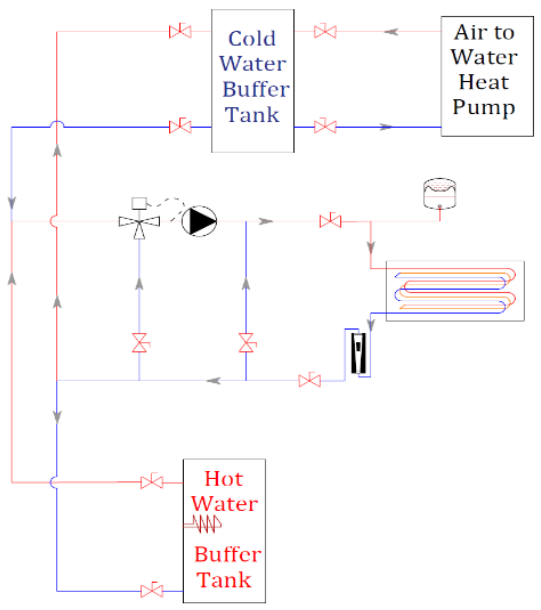

Fig. 1. Experimental rig layout.

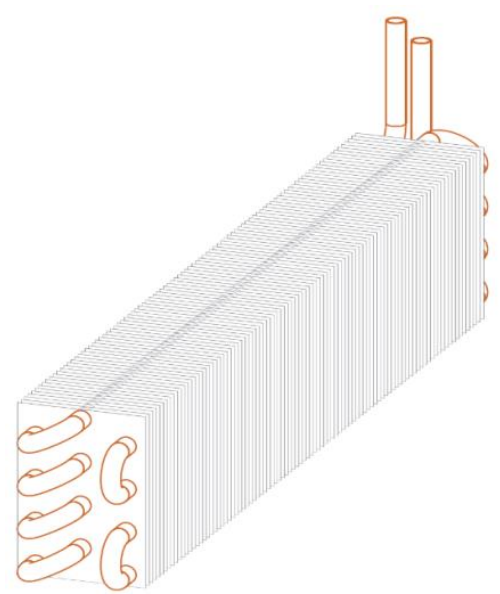

Fig. 2. Staggered heat exchanger 3D drawing. 


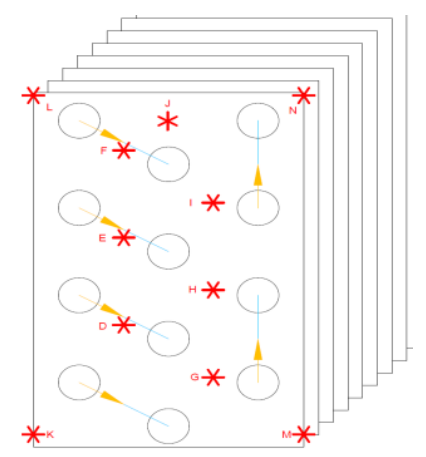

Fig. 3. Positioning of thermocouples within the PCM cavity (among heat exchanger fins).

\subsection{PCMs studied}

The selection of the PCM used, is an important parameter regarding the design of aLHTES as the amount of energy that may be recovered is directly linked to the nature of the material. The selection of PCM in this work is based on the consideration of low temperature solar thermal applications. The materials tested are commercial products of PCM PRODUCTS ${ }^{\circledR}[10]$ and their detailed thermal and physical properties provided by the company are summarised in Table 2.

Table 2. Thermal and physical properties of paraffin waxes used in the experiments [10].

\begin{tabular}{|l|c|c|c|c|}
\hline & $\mathbf{A 5 3}$ & $\mathbf{A 4 6}$ & $\mathbf{A 4 4}$ & $\mathbf{A 4 0}$ \\
\hline Melting point (K) & 324,2 & 318 & 317 & 312 \\
\hline Density liquid $\left(\mathrm{kg} / \mathrm{m}^{3}\right)$ & 775 & 775 & 775 & 775 \\
\hline Thermal conductivity solid (W/mK) & 0.22 & 0.24 & 0.24 & 0.24 \\
\hline Thermal conductivity liquid (W/mK) & 0.22 & 0.24 & 0,24 & 0.24 \\
\hline Specific heat liquid(J/kgK) & 1.8 & 1.8 & 1.8 & 1.8 \\
\hline Specific heat solid(J/kgK) & 2.4 & 2.4 & 2.4 & 2.4 \\
\hline Latent heat $(\mathrm{kJ} / \mathrm{kg})$ & $160-180$ & $185-215$ & 250 & 153 \\
\hline
\end{tabular}

\subsection{Experimental procedure and conditions tested}

The first thing to position within the glass tank was the staggered heat exchanger. The second step was the positioning of the thermocouples in a certain place throughout all experiments (Fig. 3). Hot water was then supplied to the HE and portions of solid PCM were placed onto its surface. In any case, before PCM was inserted the rig was tested for leakages. The rise in temperature of the HE walls caused PCM melting and more quantity was added to a certain volume. This was the fastest way to fill the tank with PCM and to ensure that no air was trapped within its volume. The PCM was then cooled to room temperature and the experimental procedure was performed, always following the same sequence:

(i) Charging (melting): Hot water within the buffer was circulated within the piping at a temperature rise of $8^{\circ} \mathrm{C}$ more than the melting temperature of the PCM (if A40 was examined the $\mathrm{HTF}$ temperature was $48^{\circ} \mathrm{C}$ ). Temperature inlet was controlled by the 
three-way mixing valve. Melting process was ended when the temperature of the thermocouples at the edges of the exchanger (thermocouples $\mathrm{K}, \mathrm{L}, \mathrm{M}, \mathrm{N}$ ) exceeded melting temperature more than $3^{\circ} \mathrm{C}$ (in the case of $\mathrm{A} 40$ the temperature should exceed $43^{\circ} \mathrm{C}$ ). Then solidification process was performed

(ii) Discharging (solidification): Subsequently, a discharging experiment starts just after the completion of the charging experiment. Cold water from the buffer tank was circulated with a temperature of $8^{\circ} \mathrm{C}$ less than the melting temperature of the PCM (e.g. if A40 was examined the $\mathrm{HTF}$ temperature was $32^{\circ} \mathrm{C}$ ). Temperature inlet was controlled by the three-way mixing valve. Solidification ended when the temperature of the thermocouples at the edges of the exchanger (thermocouples K, L, M, N in Fig. 3) was less than $3^{\circ} \mathrm{C}$ than melting temperature (in the case of $\mathrm{A} 40$ the temperature should exceed $37^{\circ} \mathrm{C}$ ).

To justify repeatability selected experiments were carried out three times. Fig. 4 shows thermocouples mean temperature variation for three repetitions of a charging and discharging process of A44 using aflow rate of $60 \mathrm{lt} / \mathrm{h}$ and an inlet temperature of $52^{\circ} \mathrm{C}$. A sufficient repeatability is observed.

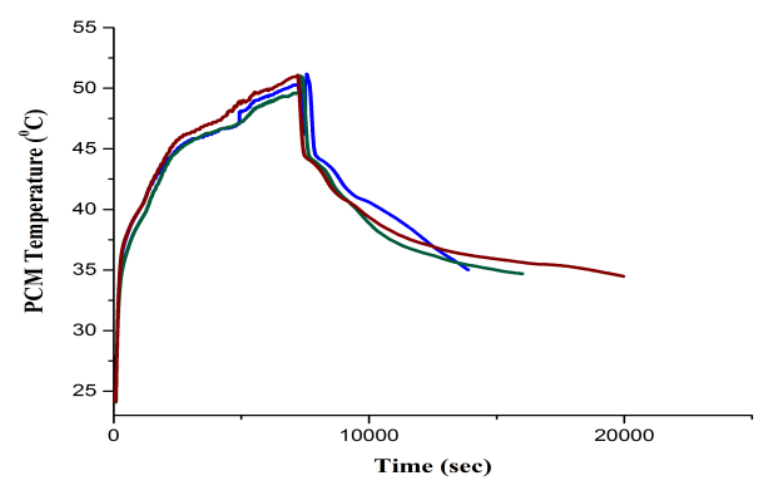

Fig. 4. Repeatability test of A44 using a flow rate of $60 \mathrm{lt} / \mathrm{h}$ and inlet water at $52^{\circ} \mathrm{C}$.

\section{Results and discussion}

Melting and solidification process of a material, in both sensible or latent heat storage procedures is related to the energy provided (charging) or extracted (discharging) by the HTF. The amount of energy is dependent on the HTF inlet temperature and flow rate. Both factors are related via the equation:

$$
q=\dot{m}_{H T F} C p_{H T F}\left(T_{\text {in }}-T_{\text {out }}\right)
$$

$\dot{m}_{H T F}=$ HTF mass flow rate $(\mathrm{kg} / \mathrm{s})$

$C p_{H T F}=$ HTF specific heat capacity $(\mathrm{kJ} / \mathrm{KgK})$

$T_{\text {in }}=\mathrm{HTF}$ inlet temperature $(\mathrm{K})$

$T_{\text {out }}=$ HTF outlet temperature $(\mathrm{K})$

$q=$ Heat Flux $(\mathrm{kJ} / \mathrm{sec})(\mathrm{q}=\mathrm{Q} / \mathrm{t})$

As mentioned above, HTF is water hence specific heat capacity is constant. All experiments were performed for two HTF flow rates: (i) $30 \mathrm{lt} / \mathrm{h}(0.0083 \mathrm{~kg} / \mathrm{s})$, and (ii) $60 \mathrm{lt} / \mathrm{h}(0.0166 \mathrm{~kg} / \mathrm{s})$. By Eq. 1 it is then concluded that the larger the value of HTF flow 
rate (for a same constant inlet temperature) the larger the heat flux by the pipes to the PCM hence the shortest the period to complete the process of charging (melting). Discharging process period is also decreased, respectively. Experimental plots confirmed what expected but not in the same rate. Melting time is affected more than solidification time when doubling HTF flow rate and this is mainly due to the alternation of heat transfer mechanism.

When charging, or discharging a PCM three different thermal and conditional states take place (shown in Fig. 5). The initial condition of the PCM when melting begins is solid. Whence HTF is starting to circulate within the HE pipes, due to conduction (between pipes and PCM) the material starts to melt. Liquid fraction increases as time progresses. Due to buoyancy within the liquid state PCM, convection heat transfer is occurring. This phenomenon increases heat transfer rate. Actually, conduction is the mechanism to transfer heat from liquid to solid PCM, but convection speeds up the process. In between altering state (solid to liquid), latent heat region is present where heat is stored to the PCM without altering its temperature. Finally, above phase change region the PCM acts as a sensible heat storage medium by storing heat and increasing its temperature. During solidification the same procedure is performed respectively.

By Eq.1, the second factor to analyse is temperature difference between inlet and outlet of the HE. As inlet temperature approaches outlet conditions, heat flux is reduced. It is then concluded that at the beginning of each experiment, heat flux takes its maximum value as temperature difference is at its maximum difference. Besides flow rate a key role regarding melting and solidification processes of a PCM is temperature variation between HTF inlet temperature and PCM temperature. These conclusions are based on the assumption that the tank containing the material has adiabatic walls, otherwise thermal losses also contribute to an extent.

During solidification processes all PCM had the same behaviour. The first region to solidify was the volume of the PCM is touch with the HE walls (as seen in Fig. 5). The formation of the solidified PCM in an axial direction round HE pipes though had a significant factor on total discharging process. The formation of this layer eliminated convection heat transfer from HE walls to the PCM. Conduction heat transfer is now the only possible method to complete solidification. As all PCM have low thermal conductivity solidification time decreases rapidly.

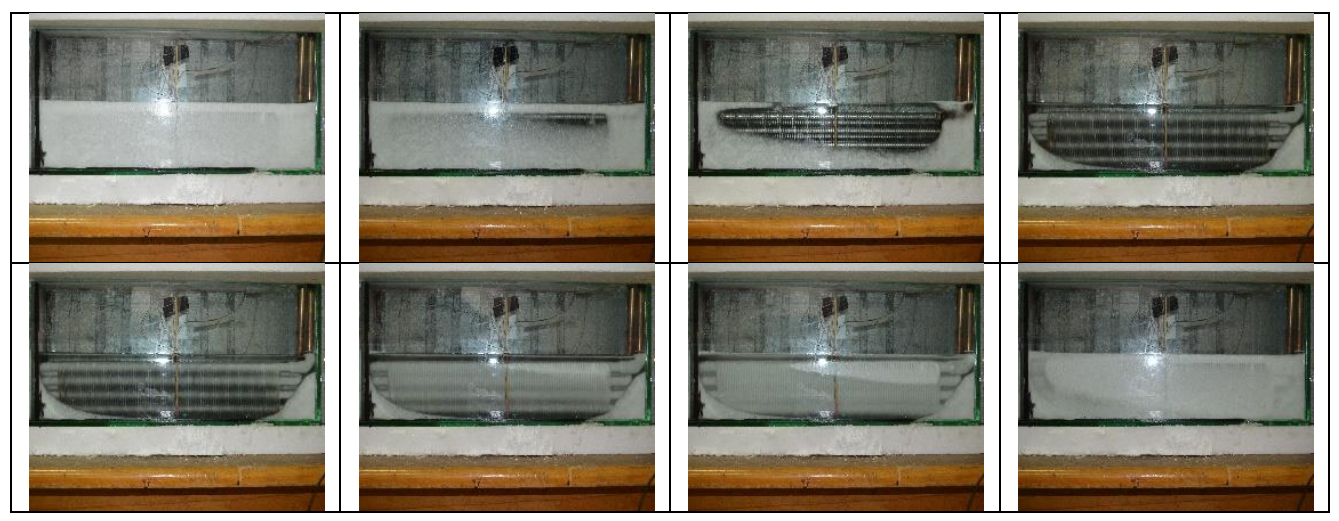

Fig. 5. Pictures showing different melting and solidification stages of A44.

There are also some other factors that affect charging and discharging processes regarding PCM thermal behaviour and these need further discussion and may be analysed in future work. HTF flow rate has to be studied regarding Reynolds number. Heat is transferred from the HTF to the walls of the HE via conduction when flow is laminar and 
convection, when flow becomes turbulent. HTF flow rate then has to be analysed regarding Reynolds number in a pipe and not simply by a value of volumetric flow rate. Another factor to be further analysed is insulation and especially that of the air above the PCM. If the amount of air is large and convective heat transfer may appear then the phenomenon is altered. Finally, the geometry of the HE or even its materials may be utilised to optimise heat flux and speed up charging and solidification processes. Plots below, show time variation for both charging and discharging processes of A40, A44, A46 and A53. Y axis presents the mean temperature value of the thermocouples placed into the PCM cavity (positioning in Fig. 3).

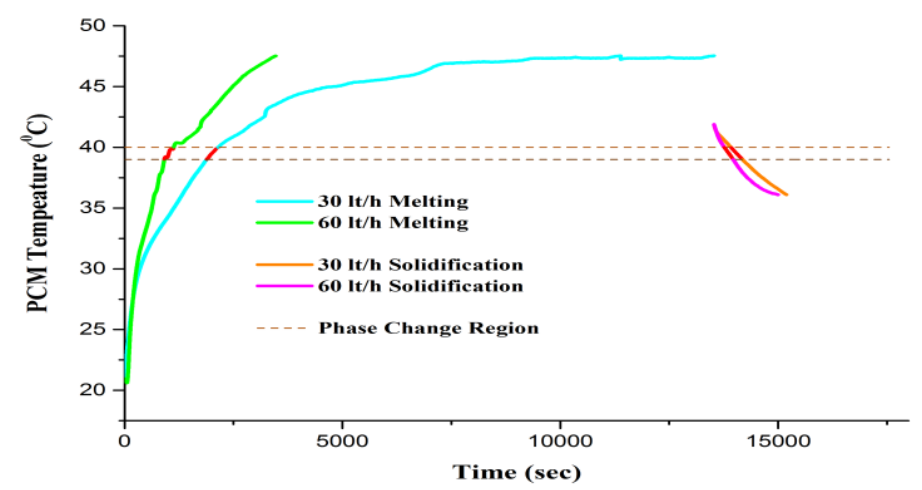

Fig. 6. Temperature profiles inside A40 for charging and discharging and various inlet feed rates.

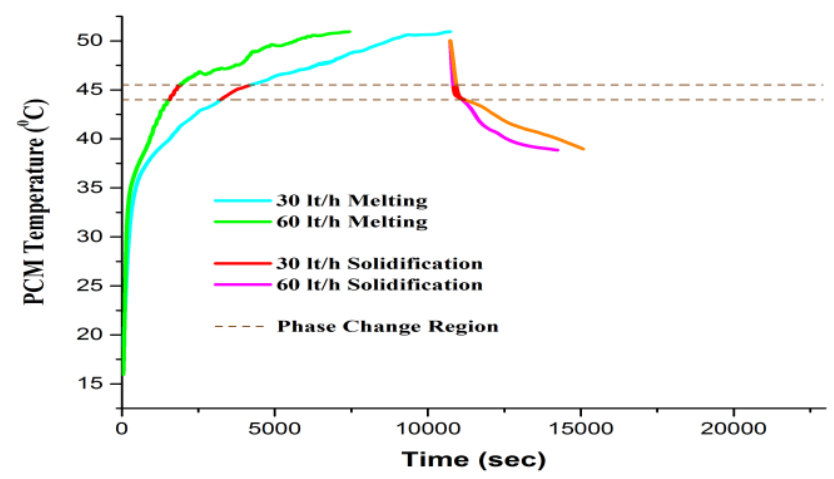

Fig. 7. Temperature profiles inside A44 for charging and discharging and various inlet feed rates. 


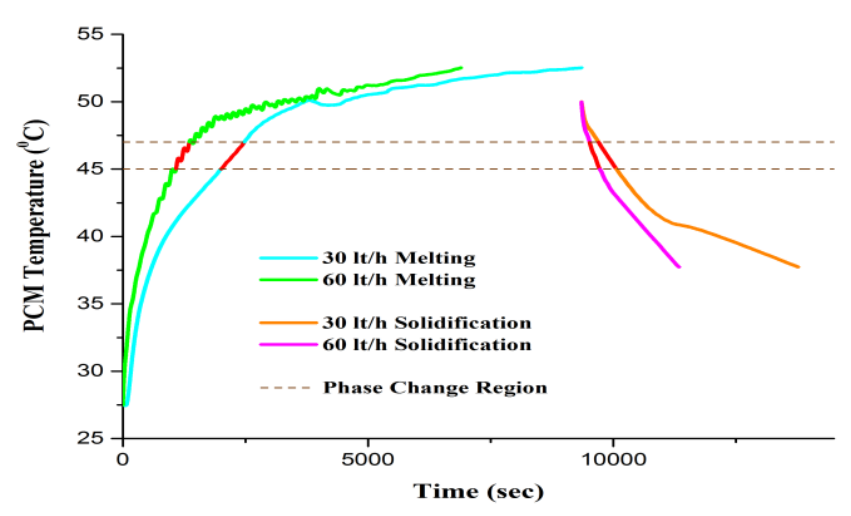

Fig. 8. Temperature profiles inside A46 for charging and discharging and various inlet feed rates.

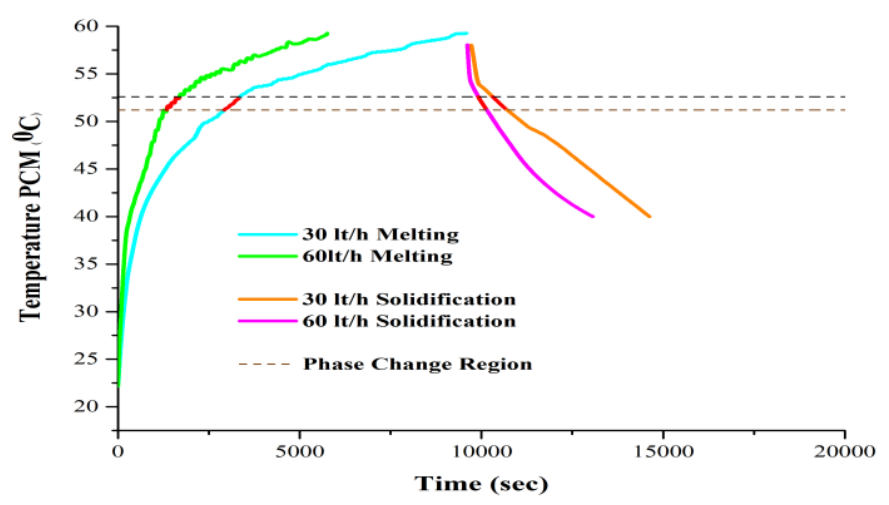

Fig. 9. Temperature profiles inside A53 for charging and discharging and various inlet feed rates.

\section{Conclusions}

This work focuses on the effect of HTF flow rate regarding charging and discharging processes of a heat storage system for four different PCM with a staggered heat exchanger. All experimental data showed that process time (in both melting and solidification) is reducing when HTF flow rate increases. The phenomenon is not analogous and it is dependent on the variation of the heat transfer mechanism occurring. During melting convection speeds up the procedure whence during solidification the formation of a solid layer around $\mathrm{HE}$ pipes, eliminates convective effects and it is only affected by conduction among the PCM.

\section{Acknowledgement}

The work is supported by TESSe $2 b$ project which has received funding from the European Union's Horizon 2020 research and innovation programme under grant agreement No 680555 . 


\section{References}

1. A. Abhat, Sol. Energy 30, 4, 313 (1983)

2. A.A. Robaidi, Int. J. Mater. Sci. Appl. 2, 6, 168 (2013)

3. L. Liu, D. Su, Y. Tang, G. Fang, Renewable and Sustainable EnergyReviews 62, 305 (2016)

4. M. Lacroix, Int. J. Heat Mass Transfer 36, 2083 (1993)

5. F. Agyenim, P. Eames, M. Smyth, Sol. Energy 83, 9, 1509 (2009)

6. A. Castell, M. Belusko, F. Bruno, L.F. Cabeza, Appl. Energy 88, 11, 4120 (2011)

7. M. Medrano, M.O. Yilmaz, M. Nogués, I. Martorell, J. Roca, L.F. Cabeza, Appl. Energy 86, 10, 2047 (2009)

8. N.H.S. Tay, M. Belusko, A. Castell, L.F. Cabeza, F. Bruno, Appl. Energy 131, 377 (2014)

9. S. Paria, S. Baradaran, A. Amiri, A.A.D. Sarhan, S.N. Kazi, J. Therm. Anal. Calorim. 123, 1371 (2016)

10. http://www.pemproducts.net 